\title{
Prognostic implications of pulmonary hypertension in patients with severe aortic stenosis
}

\author{
Akin Cam, MD, ${ }^{\mathrm{a}}$ Sachin S. Goel, MD, ${ }^{\mathrm{b}}$ Shikhar Agarwal, MD, MPH, ${ }^{\mathrm{a}}$ Venu Menon, MD, ${ }^{\mathrm{b}}$ \\ Lars G. Svensson, MD, PhD, ${ }^{\mathrm{c}}$ E. Murat Tuzcu, MD, ${ }^{\mathrm{b}}$ and Samir R. Kapadia, $\mathrm{MD}^{\mathrm{b}}$
}

\begin{abstract}
Objective: We sought to determine the clinical outcomes of patients undergoing surgical aortic valve replacement with hemodynamically confirmed severe pulmonary hypertension and aortic stenosis and compare them with the outcomes of patients not undergoing aortic valve replacement and patients undergoing aortic valve replacement with mild-to-moderate pulmonary hypertension.
\end{abstract}

\begin{abstract}
Methods: A total of 317 patients with severe aortic stenosis (aortic valve area $<1 \mathrm{~cm}^{2}$ ) underwent right heart catheterization along with left heart catheterization between 2004 and 2009. Severe pulmonary hypertension (mean pulmonary artery pressure $>35 \mathrm{~mm} \mathrm{Hg}$ ) was present in 81 patients, of whom $35(43.2 \%)$ underwent surgical aortic valve replacement. We compared the clinical outcomes of these 35 patients with the 46 patients with severe pulmonary hypertension who did not undergo surgical aortic valve replacement.
\end{abstract}

Results: Thirty-day mortality after aortic valve replacement was $2.85 \%$ in patients with severe pulmonary hypertension and $10.86 \%$ in patients not undergoing aortic valve replacement $(P=.001)$. During a mean follow-up of $339.0 \pm 343.7$ days, overall mortality in patients undergoing aortic valve replacement was $14.2 \%$ in patients with severe pulmonary hypertension and $50 \%$ in patients with severe pulmonary hypertension who did not undergo aortic valve replacement $(P<.0001)$. On the other hand, among patients who underwent surgery, overall mortality was similar in both the mild-to-moderate pulmonary hypertension group (23 patients [20.3\%]) and the severe pulmonary hypertension group at the end of the follow-up period $(P=.4)$. In a multivariate analysis, the presence of chronic obstructive pulmonary disease and the lack of reduction in mean pulmonary artery pressure were independent predictors of mortality in these high-risk patients undergoing aortic valve replacement, whereas baseline mean pulmonary artery pressure was not a predictor. Preoperative pulmonary capillary wedge pressure was a significant predictor of postoperative reduction in mean pulmonary artery pressure.

Conclusions: In patients with severe aortic stenosis and severe pulmonary hypertension who undergo aortic valve replacement, baseline pulmonary artery pressure does not unfavorably affect survival. Aortic valve replacement should be considered for patients with aortic stenosis with severe pulmonary hypertension, especially with higher pulmonary capillary wedge pressure. (J Thorac Cardiovasc Surg 2011;142:800-8)

The prevalence of pulmonary hypertension $(\mathrm{PH})(28 \%-$ $56 \%)$ and severe $\mathrm{PH}(11 \%-21 \%)$ in the setting of severe aortic stenosis (AS) varies depending on patient selection criteria and the threshold of pulmonary artery pressure (PAP) used for definition of PH. ${ }^{1-4}$ The cause of severe $\mathrm{PH}$ in this clinical setting may be attributed to left ventricular systolic or diastolic dysfunction. ${ }^{1-5}$ When present, $\mathrm{PH}$ is a harbinger for potential sudden death and clinical deterioration. $^{6}$

Although aortic valve replacement (AVR) for severe AS can be safely performed in most patients, surgical options

From the Departments of Internal Medicine, ${ }^{\mathrm{a}}$ Cardiovascular Medicine, ${ }^{\mathrm{b}}$ and Thoracic and Cardiovascular Surgery, ${ }^{\mathrm{c}}$ Cleveland Clinic, Cleveland, Ohio.

Disclosures: Authors have nothing to disclose with regard to commercial support.

Received for publication Aug 25, 2010; revisions received Nov 12, 2010; accepted for publication Dec 16, 2010; available ahead of print Feb 14, 2011.

Address for reprints: Samir R. Kapadia, MD, Professor of Medicine, Director, Cardiac Catheterization Laboratory, 9500 Euclid Ave, Desk J2-31, Cleveland, OH 44195 (E-mail: kapadis@ccf.org).

0022-5223/\$36.00

Copyright (c) 2011 by The American Association for Thoracic Surgery doi:10.1016/j.jtcvs.2010.12.024 may be limited in the elderly and in subjects with multiple comorbidities. ${ }^{7-10}$ A significant proportion of these highrisk surgical candidates may now be optimally managed using transcatheter aortic valve implantation. The availability of this less-invasive technique heightens the importance of accurate surgical risk assessment by the referring clinician. ${ }^{11}$ The ultimate decision to proceed with a conventional surgical procedure is then based on assessing the benefit that the individual patient is likely to derive over the inherent risk of the planned procedure.

Although an earlier study reported preoperative $\mathrm{PH}$ impaired long-term prognosis of patients after AVR, ${ }^{12}$ more recent studies have shown low operative mortality and excellent symptomatic improvement in patients with severe AS with severe PH after AVR, ${ }^{4,13}$ with a rapid improvement in systolic and diastolic PAPs ${ }^{13-15}$ that has translated into a favorable long-term clinical outcome. ${ }^{14,16}$ A significant limitation of these prior analyses was their dependence on echocardiography-derived estimation of systolic PAP using the tricuspid valve regurgitation jet velocity. Tricuspid valve regurgitation jet velocity can be detected in only 


$$
\begin{aligned}
& \text { Abbreviations and Acronyms } \\
& \begin{aligned}
\text { AS } & =\text { aortic stenosis } \\
\text { AVA } & =\text { aortic valve area } \\
\text { AVR } & =\text { aortic valve replacement } \\
\text { CI } & =\text { confidence interval } \\
\text { COPD } & =\text { chronic obstructive pulmonary disease } \\
& \text { HR = hazard ratio } \\
\text { LVEDP } & \text { left ventricular end-diastolic pressure } \\
\text { NYHA } & =\text { New York Heart Association } \\
\text { OR } & =\text { odds ratio } \\
\text { PCWP } & =\text { pulmonary capillary wedge pressure } \\
\text { PH } & =\text { pulmonary hypertension } \\
\text { PAP } & \text { pulmonary artery pressure } \\
\text { STS } & \text { Society of Thoracic Surgeons }
\end{aligned}
\end{aligned}
$$

$39 \%$ to $86 \%$ of patients, and $44 \%$ to $96 \%$ of these patients have enough signals for pressure measurement. ${ }^{17}$ However, right heart catheterization is the only method for direct measurement of an increased pressure in pulmonary circulatory system. Therefore, right heart catheterization has a higher specificity and is the gold standard for the diagnosis of PH. ${ }^{18,19}$ To date, only 3 catheter-based hemodynamic studies with small patient numbers have been published in this population with limited survival data. ${ }^{1,413}$ Data on shortand long-term mortality and predictors of mortality are also lacking. Although postoperative reduction in PAP has been shown after AVR, ${ }^{13-15}$ it is not clear which patients will respond favorably and whether a favorable hemodynamic response predicts better outcome in this clinical subset. Accordingly, we reviewed our experience to determine the prognostic effect of catheter-diagnosed severe $\mathrm{PH}$ in patients with severe AS by using catheterizationbased hemodynamic data.

\section{MATERIALS AND METHODS Study Population}

We retrospectively reviewed patient records at the Cleveland Clinic from January 2004 to April 2009 to determine patients with severe AS (aortic valve area $[\mathrm{AVA}]<1 \mathrm{~cm}^{2}$ ) who underwent right and left heart catheterization. Patients with clinically severe chronic obstructive pulmonary disease (COPD) (a volume of air exhaled within the first second of forced expiratory maneuver $<50 \%$ of predicted value and forced expiratory volume in 1 second/forced vital capacity $<0.7$ ), primary $\mathrm{PH}$ from medical history, interstitial lung disease (eg, diseases involving the parenchyma of the lung, idiopathic pulmonary fibrosis, connective tissue disease, asbestosis, sarcoidosis), concomitant severe mitral stenosis, or previous AVR were excluded. We identified 317 patients with severe AS who had undergone both left and right heart catheterization during the study period. Severe $\mathrm{PH}$ was defined as mean PAP greater than $35 \mathrm{~mm} \mathrm{Hg} .{ }^{20}$ In our data set, 81 patients had severe PH and 35 of them (43.2\%) underwent surgical AVR. On the other hand, 236 patients had mild-to-moderate PH (mean PAP $\leq 35 \mathrm{~mm}$ $\mathrm{Hg}$ ) and 114 of these patients underwent surgical AVR. We compared the clinical outcomes of patients with severe PH who underwent surgical
AVR with those who did not undergo surgical AVR and with patients with mild-to-moderate $\mathrm{PH}$ who underwent surgical AVR.

Baseline patient characteristics and clinical follow-up variables were obtained from medical records after the Cleveland Clinic Institutional Review Board approved our study. Age, gender, body mass index, symptoms (angina, dyspnea, or syncope and presyncope), aortic valve morphology, functional New York Heart Association (NYHA) class, creatinine level, smoking history, hypertension, diabetes, COPD, myocardial infarction, coronary artery bypass graft surgery, significant coronary artery disease (stenosis $>50 \%$ ), and atrial fibrillation were noted as baseline characteristics at the time of index heart catheterization. We also calculated predicted Society of Thoracic Surgeons (STS) surgical risk scores of all patients using the STS website (http://209.220.160.181/STSWebRiskCalc261/).

Date of surgery, concomitant surgeries, postoperative complications, length of hospital stay, and postoperative NYHA class were recorded for surgical outcomes. Postoperative death, repeated sternotomy, prolonged ventilation (ventilation $>48$ hours), tracheostomy, atrial fibrillation, permanent pacemaker, acute myocardial infarction, stroke, chronic renal insufficiency ( $>2 \mathrm{mg} / \mathrm{dL}$ creatinine or $>1 \mathrm{mg} / \mathrm{dL}$ increase), dialysis, multiorgan failure, and sepsis were considered as postoperative complications.

We searched the Social Security Death Index in May 2009 to determine mortality. Date of surgery was the origin for survival analysis, and mortality outcomes included all deaths to May 2009. In patients who did not undergo surgery, the date of index right heart catheterization was the zero point for survival analysis. Death within 1 month after surgery or index heart catheterization (for no AVR group) was defined as 30-day mortality.

\section{Echocardiographic Methods}

Echocardiographic data were obtained from the last available 2-dimensional and Doppler transthoracic echocardiography before index heart catheterization. Effective AVA using the continuity equation, left ventricular ejection fraction, mean and peak aortic transvalvular gradients using continuous-wave Doppler across the left ventricular outflow tract, and presence of concurrent aortic valve insufficiency, mitral valve regurgitation, mitral stenosis, and right ventricle systolic dysfunction were noted from echocardiographic studies.

\section{Hemodynamic Methods}

Right and left cardiac catheterization and coronary angiography were performed according to physician judgment for patients with severe AS. AVA, peak gradient, mean gradient, systolic PAP, diastolic PAP, mean PAP, mean pulmonary capillary wedge pressure (PCWP), cardiac output and cardiac index (Fick method), and left ventricular end-diastolic pressure (LVEDP) were obtained from cardiac catheterization laboratory records. Pulmonary vascular resistance was calculated in units of dynes $/ \mathrm{sec} / \mathrm{cm}^{-5}$ as $80 \times($ mean PAP - mean PCWP)/cardiac output. We evaluated postoperative changes of systolic PAP, diastolic PAP, and mean PAP using SwanGanz catheter-derived pressures in the postoperative intensive care unit The last reading before withdrawing the catheter was accepted for analysis. The change in mean PAP after surgery was also assessed.

\section{Statistical Analysis}

Statistical analysis was performed using Stata v. 10.0 (StataCorp LP, College Station, Tex) statistical software. Bivariate comparisons between the mild-to-moderate and severe PH groups were drawn using the Student $t$ test and Kruskal-Wallis test for continuous and discrete data, respectively. Unadjusted Kaplan-Meier survival analysis was used to compare longterm mortality between the 2 groups. After verification of standard modeling assumptions, we used a Cox proportional hazards modeling approach to determine significant predictors of mortality in our study population. On the basis of reduction of mean PAP, the study population was divided into 2 groups: responders (patients with $\geq 10 \mathrm{~mm} \mathrm{Hg}$ decrease in mean PAP after AVR) and nonresponders (patients with $<10 \mathrm{~mm} \mathrm{Hg}$ decrease 
in mean PAP after AVR). A multivariate logistic regression analysis was carried out to determine significant predictors of response post-AVR.

\section{RESULTS \\ Baseline Characteristics}

For the study period (January 2004 to April 2009), we identified 317 patients with severe AS who underwent left and right heart catheterization and met all eligibility criteria. Among these patients, $81(25.2 \%)$ had severe PH. A total of 35 of 81 patients $(43.2 \%$ ) (mean PAP range, $36-74 \mathrm{~mm} \mathrm{Hg}$ ) underwent AVR during the study period, and 46 patients did not. Among the patients with mild-to-moderate PH, 114 underwent AVR during the study period.

Table 1 shows the baseline characteristics of patients undergoing AVR. In this population selected to receive a right heart catheterization, the severe PH group was significantly older than the mild-to-moderate PH group. Compared with patients in the mild-to-moderate PH group, those in the severe $\mathrm{PH}$ group more frequently had diabetes and atrial fibrillation. The clinical presentation of both groups had similar frequencies of angina, dyspnea, and syncopepresyncope, but more patients in the severe PH group were in NYHA class 3 to 4 . Mean serum creatinine levels and mean calculated STS scores were higher in the severe $\mathrm{PH}$ group.

Baseline echocardiographic and hemodynamic characteristics of patients undergoing AVR are presented in Table 1. In the mild-to-moderate PH group, more patients had a bicuspid aortic valve. Average baseline AVA was lower in the severe PH group (mean [standard deviation]: $0.67 \pm 0.2 \mathrm{~cm}^{2}$ vs. $0.75 \pm 0.1 \mathrm{~cm}^{2}, P=.02$ ), but average baseline peak and mean gradients across the aortic valve were similar in both groups. Furthermore, average baseline left ventricular ejection fraction was lower in the severe $\mathrm{PH}$ group compared with the mild-to-moderate $\mathrm{PH}$. The severe PH group had higher preoperative LVEDP, PCWP, and mean pulmonary vascular resistance. Average systolic PAP was $36.4 \pm 9.4 \mathrm{~mm} \mathrm{Hg}$ in the mild-to-moderate $\mathrm{PH}$ group and $70.5 \pm 14.6 \mathrm{~mm} \mathrm{Hg}$ in the severe PH group. In all the patients in the severe $\mathrm{PH}$ group, systolic PAP was $\geq 55 \mathrm{~mm} \mathrm{Hg}$. Moderate-to-severely depressed right ventricle systolic function was observed in 6 patients $(5.26 \%)$ in the mild-to-moderate $\mathrm{PH}$ group and in 2 patients $(5.71 \%)$ in the severe $\mathrm{PH}$ group $(P=.9)$.

Patients with severe PH who did not undergo AVR had similar age $(76.3 \pm 11.5$ years), gender distribution (male $67 \%)$, mean PAP $(44.2 \pm 6.3 \mathrm{~mm} \mathrm{Hg})$, cardiac index $(2.2$ $\pm 0.7)$, and STS scores $(5.7 \pm 3.7)$ compared with patients with severe PH who did not undergo AVR. The reasons for not undergoing surgery are listed in Table 2.

\section{Operations}

In addition to AVR, 51 patients $(44.73 \%)$ in the mildto-moderate $\mathrm{PH}$ group and 13 patients $(37.14 \%)$ in the
TABLE 1. Baseline characteristics of patients with aortic valve replacement

\begin{tabular}{|c|c|c|c|}
\hline Characteristic & $\begin{array}{c}\text { Mild-to-moderate } \\
\text { PH }(n=114)\end{array}$ & $\begin{array}{c}\text { e Severe PH } \\
(\mathbf{n}=\mathbf{3 5})\end{array}$ & $\begin{array}{c}P \\
\text { value }\end{array}$ \\
\hline Mean (SD) age (y) & $71(12)$ & $75(10)$ & .04 \\
\hline Male $(\%)$ & $61(53.5)$ & $18(51.4)$ & .8 \\
\hline Smoking history (\%) & $61(53.5)$ & $16(45.7)$ & .4 \\
\hline Mean (SD) BMI $\left(\mathrm{kg} / \mathrm{m}^{2}\right)$ & $28.2(5.8)$ & $30.1(6.8)$ & .1 \\
\hline \multicolumn{4}{|l|}{ Medical history $(\%)$} \\
\hline Hypertension & $83(72.8)$ & $28(80)$ & .4 \\
\hline Diabetes mellitus & $28(24.6)$ & $16(45.7)$ & .02 \\
\hline Prior myocardial infarction & $26(22.8)$ & $7(20)$ & .7 \\
\hline COPD & $29(25.4)$ & $8(22.9)$ & .8 \\
\hline Atrial fibrillation & $27(23.7)$ & $14(40)$ & .06 \\
\hline \multicolumn{4}{|l|}{ Symptoms (\%) } \\
\hline Angina & $24(21.1)$ & $4(11.4)$ & .2 \\
\hline Presyncope/syncope & $19(16.7)$ & $2(5.7)$ & .1 \\
\hline Dyspnea & $83(72.8)$ & $30(85.7)$ & .1 \\
\hline NYHA class $3 / 4$ & $21(18.4)$ & $16(45.7)$ & .001 \\
\hline Mean (SD) STS score & $3.6(2.8)$ & $6.9(3.9)$ & $<.001$ \\
\hline $\begin{array}{l}\text { Mean (SD) serum creatinine } \\
\quad(\mathrm{mg} / \mathrm{dL})\end{array}$ & $1.1(0.4)$ & $1.8(1.8)$ & .02 \\
\hline \multicolumn{4}{|l|}{ Echocardiographic measurements } \\
\hline Mean (SD) AVA $\left(\mathrm{cm}^{2}\right)$ & $0.75(0.1)$ & $0.67(0.2)$ & .02 \\
\hline Bicuspid valve $(\%)$ & $25(21.9)$ & $1(2.9)$ & .009 \\
\hline $\begin{array}{l}\text { Average }(\mathrm{SD}) \text { baseline left } \\
\text { ventricular ejection fraction } \\
\text { percent }\end{array}$ & $53.1(12.3)$ & $44.1(13.7)$ & .001 \\
\hline $\begin{array}{l}\text { Average (SD) baseline peak } \\
\text { gradient across aortic valve } \\
(\mathrm{mm} \mathrm{Hg})\end{array}$ & $67.8(25.3)$ & $66.9(21.9)$ & .9 \\
\hline $\begin{array}{l}\text { Average (SD) baseline mean } \\
\text { gradient across aortic valve } \\
(\mathrm{mm} \mathrm{Hg})\end{array}$ & $38.7(16.0)$ & $39.3(15.4)$ & .8 \\
\hline \multicolumn{4}{|l|}{ Hemodynamic measurements } \\
\hline $\begin{array}{l}\text { Average (SD) baseline systolic } \\
\text { PAP (mm Hg) }\end{array}$ & $36.4(9.4)$ & $70.5(14.6)$ & $<.001$ \\
\hline $\begin{array}{l}\text { Average (SD) baseline diastolic } \\
\text { PAP }(\mathrm{mm} \mathrm{Hg})\end{array}$ & $15.6(5.5)$ & $31.5(7.1)$ & $<.001$ \\
\hline $\begin{array}{l}\text { Average (SD) baseline mean } \\
\text { PAP (mm Hg) }\end{array}$ & $22.5(6.6)$ & $45.3(8.3)$ & $<.001$ \\
\hline $\begin{array}{l}\text { Average (SD) baseline PCWP } \\
\quad(\mathrm{mm} \mathrm{Hg})\end{array}$ & $14.6(6.1)$ & $26.8(7.0)$ & $<.001$ \\
\hline $\begin{array}{l}\text { Average (SD) baseline cardiac } \\
\text { index }\left(\mathrm{L} / \mathrm{min} / \mathrm{m}^{2}\right)\end{array}$ & $2.5(0.7)$ & $2.7(3.1)$ & .7 \\
\hline $\begin{array}{l}\text { Average (SD) baseline LVEDP } \\
\quad(\mathrm{mm} \mathrm{Hg})\end{array}$ & $16.0(6.4)$ & $24.9(9.1)$ & $<.001$ \\
\hline $\begin{array}{l}\text { Average (SD) baseline } \\
\text { pulmonary vascular } \\
\text { resistance }\left(\text { dynes } / \mathrm{sec} / \mathrm{cm}^{-5}\right)\end{array}$ & $151.6(89.9)$ & $399.3(215.6)$ & $<.001$ \\
\hline
\end{tabular}

severe PH group underwent concomitant coronary artery bypass grafting $(P=.09)$. On the other hand, 13 patients $(11.4 \%)$ in the mild-to-moderate $\mathrm{PH}$ group and 8 patients 
TABLE 2. Reasons why patients with severe aortic stenosis and severe pulmonary hypertension were not selected for aortic valve replacement

\begin{tabular}{lc}
\hline \multicolumn{1}{c}{ Reason } & $\begin{array}{c}\text { Medical treatment } \\
(\mathbf{n}=\mathbf{4 6})\end{array}$ \\
\hline $\begin{array}{l}\text { Cardiac conditions } \\
\text { (severe left ventricle dysfunction, cardiogenic }\end{array}$ & $8(17.4 \%)$ \\
$\quad$ shock, severe mitral regurgitation, porcelain aorta) & \\
Malignancy & $2(4.3 \%)$ \\
$\quad$ (lung cancer, lymphoma) & $22(47.9 \%)$ \\
Other & \\
$\quad$ (severe debilitation, end-stage liver disease, \\
$\quad$ end-stage kidney disease, cerebrovascular \\
$\quad$ accident, sepsis, pulmonary embolus, major \\
$\quad$ bleeding, connective tissue disease, amyloidosis) \\
Patient's preference \\
Asymptomatic \\
\hline
\end{tabular}

$(22.35 \%)$ in the severe PH group underwent concomitant mitral valve replacement $(P=.032)$.

\section{Follow-up, Mortality, and Postoperative Complications}

Postoperative patient characteristics of patients undergoing AVR are presented in Table 3. Mean follow-up was 548 \pm 530 days in the mild-to-moderate $\mathrm{PH}$ group and $347 \pm$ 347 days in the severe PH group $(P=.01)$. Seven deaths $(6.14 \%)$ in the mild-to-moderate $\mathrm{PH}$ group and 1 death $(2.85 \%)$ in the severe $\mathrm{PH}$ group were observed within the 30-day postoperative period $(P=.5)$. One-year mortality

TABLE 3. Postoperative characteristics of patients with aortic valve replacement

\begin{tabular}{lccc}
\hline \multicolumn{1}{c}{ Characteristic } & $\begin{array}{c}\text { Mild-to-moderate } \\
\text { PH }\end{array}$ & $\begin{array}{c}\text { Severe } \\
\text { PH }\end{array}$ & $\begin{array}{c}\boldsymbol{P} \\
\text { value }\end{array}$ \\
\hline $\begin{array}{l}\text { Mean (SD) follow up available } \\
\text { in days }\end{array}$ & $548(530)$ & $347(347)$ & .01 \\
Total deaths encountered to end & $23(20.2)$ & $5(14.3)$ & .4 \\
$\quad$ of follow-up period (\%) & & & \\
Death in 1 y after AVR (\%) & $17(14.9)$ & $3(8.6)$ & .3 \\
Mean (SD) length of hospital & $12.7(10.7)$ & $17.1(12.3)$ & .09 \\
$\quad$ stay in days & & & \\
NYHA class 3/4 (\%) & $26(22.8)$ & $11(31.4)$ & .3 \\
Postoperative complications (\%) & & & \\
Stroke & $3(2.6)$ & $1(2.9)$ & .9 \\
Renal insufficiency & $11(9.7)$ & $5(14.3)$ & .4 \\
Dialysis & $2(1.8)$ & $1(2.9)$ & .7 \\
Sepsis & $5(4.4)$ & $2(5.7)$ & .7 \\
Multiorgan failure & $2(1.8)$ & $1(2.9)$ & .7 \\
Permanent pacemaker & $6(5.3)$ & $1(2.9)$ & .6 \\
$\quad$ placement & & & \\
Atrial fibrillation & $26(22.8)$ & $9(25.7)$ & .7 \\
$\quad$ Tracheostomy & $9(7.9)$ & $4(11.4)$ & .5 \\
\hline
\end{tabular}

$S D$, Standard deviation; $A V R$, aortic valve replacement; $P H$, pulmonary hypertension; NYHA, New York Heart Association. was $14.9 \%$ (17 deaths) in the mild-to-moderate $\mathrm{PH}$ group and $8.6 \%$ (3 deaths) in the severe $\mathrm{PH}$ groups $(P=.3)$. Overall mortality was $23(20.2 \%)$ in the mild-to-moderate $\mathrm{PH}$ group and $5(14.2 \%)$ in the severe $\mathrm{PH}$ group $(P=.4)$ at the end of follow-up period. In the mild-to-moderate $\mathrm{PH}$ group, cardiopulmonary events (17 patients), alveolar hemorrhage (1 patient), lung cancer (1 patient), sepsis (1 patient), ischemic bowel (1 patient), acute lymphocytic leukemia (1 patient), and multiorgan failure (1 patient) were causes of death. In the severe $\mathrm{PH}$ group, cardiopulmonary events (3 patients), sepsis (1 patient), and ischemic bowel (1 patient) were causes of death. Length of hospital stay was not significantly different in the severe and nonsevere $\mathrm{PH}$ groups. In both groups, similar percentages of patients were in NYHA class 3 or 4 after surgery. Postoperative complications were also similar in both groups. Three patients in the mild-to-moderate $\mathrm{PH}$ group and 2 patients in the severe $\mathrm{PH}$ group had pneumonia in the postoperative period. In the mild-to-moderate $\mathrm{PH}$ group, 20 patients required intubation more than 24 hours ( $>72$ hours in 14 patients), whereas 8 patients required intubation more than 24 hours ( $>72$ hours in 5 patients) in the severe $\mathrm{PH}$ group. There was no significant difference in median-term mortality between the mild-to-moderate and severe PH groups, as seen in the Kaplan-Meier unadjusted analysis $(P=.8)$ (Figure 1).

In patients with severe PH who did not undergo AVR, 5 deaths $(10.86 \%)$ were observed during the 30 days after index heart catheterization. Among these patients, 1-year mortality and overall mortality at the end of study period were $39.13 \%$ (18 deaths) and 50\% (23 deaths), respectively. In this patient group, 10 patients $(21.7 \%)$ underwent balloon aortic valvuloplasty during the study period. In the Kaplan-Meier unadjusted analysis, patients with severe AS who underwent AVR had significantly better survival compared with patients with severe AS who did not undergo surgery $(P=.002)$ (Figure 2). In the mild-to-moderate $\mathrm{PH}$ group, overall mortality was higher in patients not undergoing AVR (36 deaths among 112 patients) compared with patients undergoing AVR $(P=.03)$.

\section{Predictors of Mortality in Patients With Aortic Valve Replacement}

In patients undergoing AVR, baseline mean PAP was not an independent predictor of mortality in adjusted analysis (hazard ratio [HR], 1.008; 95\% confidence interval [CI], $0.91-1.11 ; P=.86)$. However, early postoperative reduction in mean PAP was an independent predictor (HR, $0.93 ; 95 \% \mathrm{CI}, 1.2-12.5 ; P=.048)$. In addition, COPD was found to be an independent predictor of mortality (HR, 3.5; 95\% CI, 1.29-9.59; $P=.014$ ). Age, gender, body mass index, valve morphology, NHYA class, hypertension, diabetes, atrial fibrillation, smoking history, 


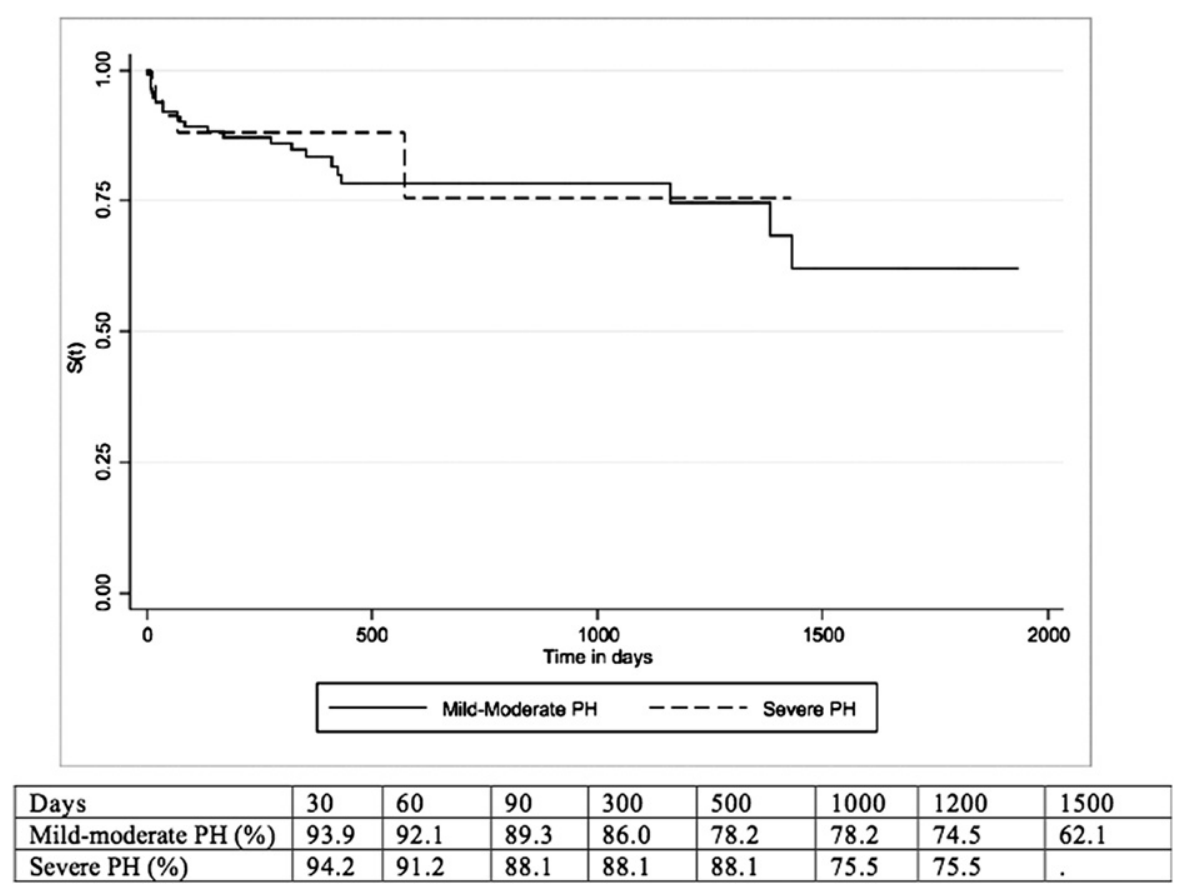

FIGURE 1. Kaplan-Meier curves comparing survival in the mild-to-moderate and severe PH groups with AVR ( $P$ value using log rank statistic: .8).

previous myocardial infarction, creatinine, AVA, peak transvalvular aortic gradient, mean PCWP, pulmonary vascular resistance, STS score, and concomitant mitral valve replacement did not predict mortality in patients with severe
AS who underwent AVR. Only 5 deaths occurred in patients with baseline mean PAP greater than $35 \mathrm{~mm} \mathrm{Hg}$. Furthermore, postoperative mean PAP in 4 of these 5 deaths was still $35 \mathrm{~mm} \mathrm{Hg}$ or greater (Figure 3).

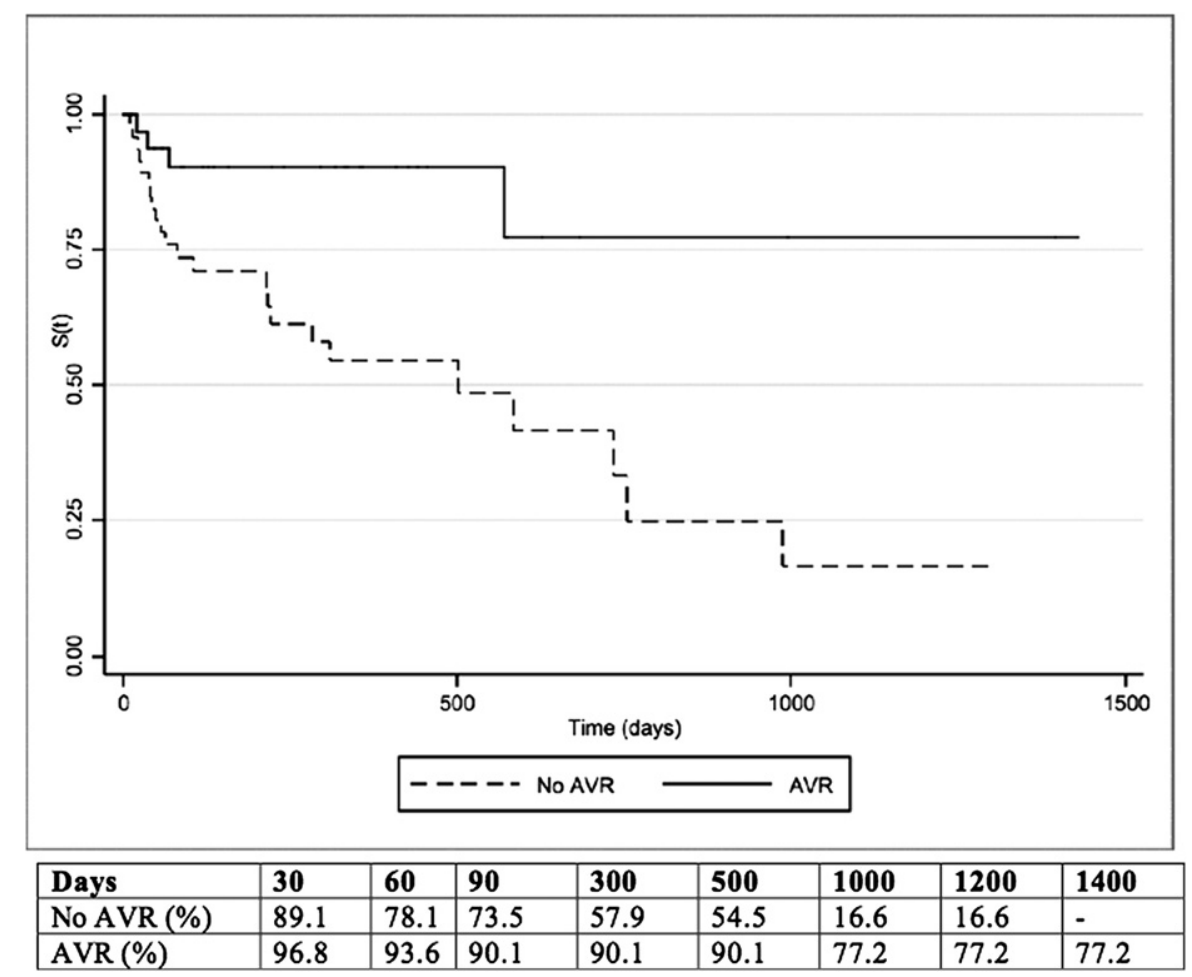

FIGURE 2. Kaplan-Meier curves comparing survival in the AVR and non-AVR groups among patients with severe PH ( $P$ value using log rank statistic: $.002)$. 


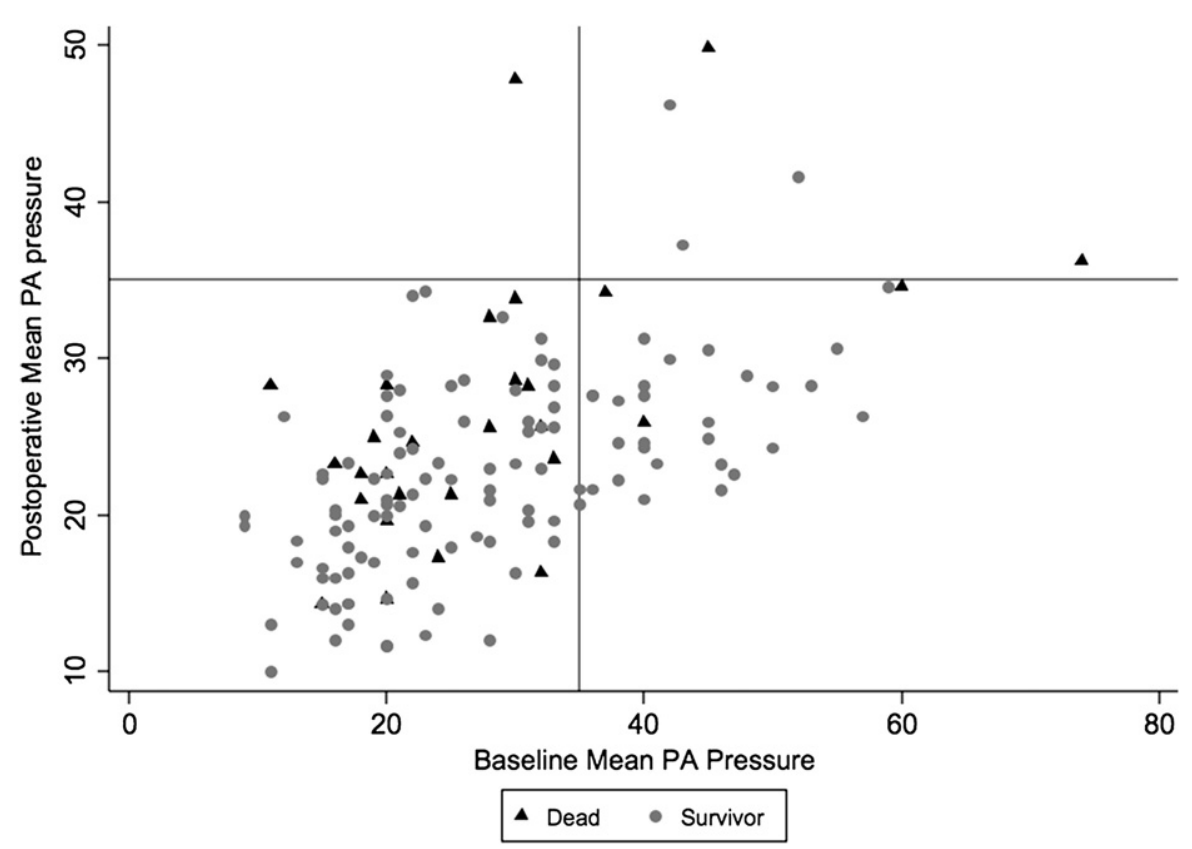

FIGURE 3. Two-dimensional scatter plot with preoperative mean PAP on the $x$ axis and postoperative mean PAP on the $y$ axis stratified by death.

\section{Postoperative Pulmonary Artery Pressure Change in Patients With Aortic Valve Replacement}

Systolic PAP reduction was significant in both severe and mild-moderate PH groups (Table 4), whereas diastolic and mean PAP reductions were significant only in the severe $\mathrm{PH}$ group. In the severe $\mathrm{PH}$ group, preoperative and postoperative mean PAPs were $45.3 \pm 8.3 \mathrm{~mm} \mathrm{Hg}$ and $29.0 \pm 6.8$ $\mathrm{mm} \mathrm{Hg}$, respectively $(P<.001)$; however, in the mild-tomoderate $\mathrm{PH}$ group these were $22.5 \pm 6.6 \mathrm{~mm} \mathrm{Hg}$ and $21.7 \pm 6.1 \mathrm{~mm} \mathrm{Hg}$, respectively $(P=.1)$. In patients with severe PH who did not require concomitant MVR, there was a significant reduction in mean PAP after surgery. In

TABLE 4. Comparison of preoperative and postoperative hemodynamic changes in patients with aortic valve replacement

\begin{tabular}{|c|c|c|c|c|}
\hline Characteristic & Preoperative & Postoperative & $\begin{array}{c}P \\
\text { value }\end{array}$ & $\begin{array}{c}\text { Net } \\
\text { change }\end{array}$ \\
\hline \multicolumn{5}{|l|}{ Systolic PAP (mm Hg) } \\
\hline Mild-to-moderate PH & $36.4(9.4)$ & $34.1(10.3)$ & .008 & $-2.7(10.2)$ \\
\hline Severe PH & 70.5 (14.6) & $47.9(12.0)$ & $<.001$ & $-22.5(14.4)$ \\
\hline$P$ value & $<.001$ & $<.001$ & & \\
\hline \multicolumn{5}{|l|}{ Diastolic PAP (mm Hg) } \\
\hline Mild-to-moderate PH & $15.6(5.5)$ & $15.6(4.9)$ & .9 & $-0.01(6.5)$ \\
\hline Severe PH & $31.5(7.1)$ & $19.7(5.4)$ & $<.001$ & $-11.8(7.6)$ \\
\hline$P$ value & $<.001$ & $<.001$ & & \\
\hline \multicolumn{5}{|l|}{ Mean PAP (mm Hg) } \\
\hline Mild-to-moderate $\mathrm{PH}$ & $22.5(6.6)$ & $21.7(6.1)$ & .1 & $-0.9(7.0)$ \\
\hline Severe PH & $45.3(8.3)$ & $29.0(6.8)$ & $<.001$ & $-16.2(9.0)$ \\
\hline$P$ value & $<.001$ & $<.001$ & & \\
\hline
\end{tabular}

$P A P$, Pulmonary artery pressure; $P H$, pulmonary hypertension. A negative net change implies reduction as compared with the preoperative value. All values expressed as mean (SD). these patients, preoperative and postoperative mean PAPs were $44.6 \pm 8.2 \mathrm{~mm} \mathrm{Hg}$ and $27.2 \pm 4.4 \mathrm{~mm} \mathrm{Hg}$, respectively $(P<.001)$. In a detailed analysis, we determined that, in both the mild-to-moderate $\mathrm{PH}$ and severe $\mathrm{PH}$ groups, patients who survived showed significant reductions in their mean PAP after AVR (Table 5). However, this reduction was not significant among patients who did not survive.

The study population was divided into 2 groups (responders and nonresponders), and a multivariate prediction modeling based on semiparametric Cox proportional hazard modeling was performed to determine preoperative predictors of reduction in mean PAP (Figure 4). High preoperative PCWP (odds ratio [OR], 1.26; 95\% CI, 1.13-1.41; $P<.0001)$ was a significant preoperative predictor of reduction of mean PAP. AVA (OR, 0.01; 95\% CI, 0.0001-1.03; $P=.052)$, atrial fibrillation (OR, $0.27 ; 95 \% \mathrm{CI}, 0.06-$ 1.08; $P=.066$ ), and previous myocardial infarction (OR, $0.22 ; 95 \%$ CI, $0.04-1.16 ; P=.075$ ) tended to be predictors of reduced mean PAP, but they remained statistically insignificant.

\section{DISCUSSION}

In our study group, mortality after AVR was similar whether patients had mild-to-moderate or severe PH. Postoperative morbidities, postoperative NYHA class III to IV, and length of hospital stay also were similar in both mildto-moderate and severe $\mathrm{PH}$ groups. In a multivariate analysis, COPD and postoperative reduction in mean PAP were independent predictors of mortality but not the baseline PAP. Preoperative high mean PCWP was a significant 
TABLE 5. Mean pulmonary artery pressure changes postoperatively compared with baseline preoperative pulmonary artery pressures stratified by mortality at the end of follow-up

\begin{tabular}{|c|c|c|c|c|}
\hline \multirow{2}{*}{$\frac{\text { Characteristic }}{\text { Mild-to-moderate } \mathrm{PH}}$} & \multicolumn{2}{|c|}{ Dead $(n=28)$} & \multicolumn{2}{|c|}{ Survivors $(n=121)$} \\
\hline & Preoperative mean PAP & $23.6(6.3)$ & Preoperative mean PAP & $22.5(6.8)$ \\
\hline & Postoperative mean PAP & $24.6(7.2)$ & Postoperative mean PAP & $20.9(5.5)$ \\
\hline & Net change: & $1.0(7.7)$ & Net change & $-1.5(6.7)$ \\
\hline & $P$ value & .5 & $P$ value & .04 \\
\hline \multirow[t]{4}{*}{ Severe PH } & Preoperative mean PAP & $51.2(15.5)$ & Preoperative mean PAP & $44.3(6.4)$ \\
\hline & Postoperative mean PAP & $36.1(8.7)$ & Postoperative mean PAP & $27.9(5.8)$ \\
\hline & Net change & $-15.1(36.3)$ & Net change & $-16.4(7.4)$ \\
\hline & $P$ value & 0.1 & $P$ value & $<.001$ \\
\hline
\end{tabular}

$\overline{P H}$, Pulmonary hypertension; $P A P$, pulmonary artery pressure. A negative net change implies reduction compared with the preoperative value. All values expressed as mean (SD).

predictor of this reduction in mean PAP. Patients with severe PH had higher preoperative LVEDP and pulmonary vascular resistance compared with the mild-to-moderate $\mathrm{PH}$ group, and they had a rapid and prominent reduction in PAP after AVR.

The significance of high PAP in patients with severe AS remains controversial. A correlation has been demonstrated between increased PAP and left ventricle diastolic dysfunction in patients with severe AS. ${ }^{1-3,5,13,14}$ It is possible that severe $\mathrm{PH}$ is reactive in these patients and does not represent pulmonary vascular disease. ${ }^{3,14}$ Some studies have demonstrated rapid reduction in systolic, diastolic, and mean PAP after AVR, resulting in improvement in clinical outcomes. ${ }^{4,13}$ Further, it has been suggested that there is better survival with AVR compared with medical management in these patients. ${ }^{14,16}$ Mortality after AVR varies in different studies depending on concomitant morbidities, exclusion criteria, and definition for severe PH. For instance, a recent report showed 34\% mortality at 5 -year follow-up, ${ }^{16}$ whereas Malouf and coworkers ${ }^{14}$ reported $32 \%$ mortality at a median of 460 days follow-up. In the latter study, only $26 \%$ of the study population (12/47 patients) underwent formal right heart catheterization. ${ }^{14}$ In another echocardiography-based study, long-term

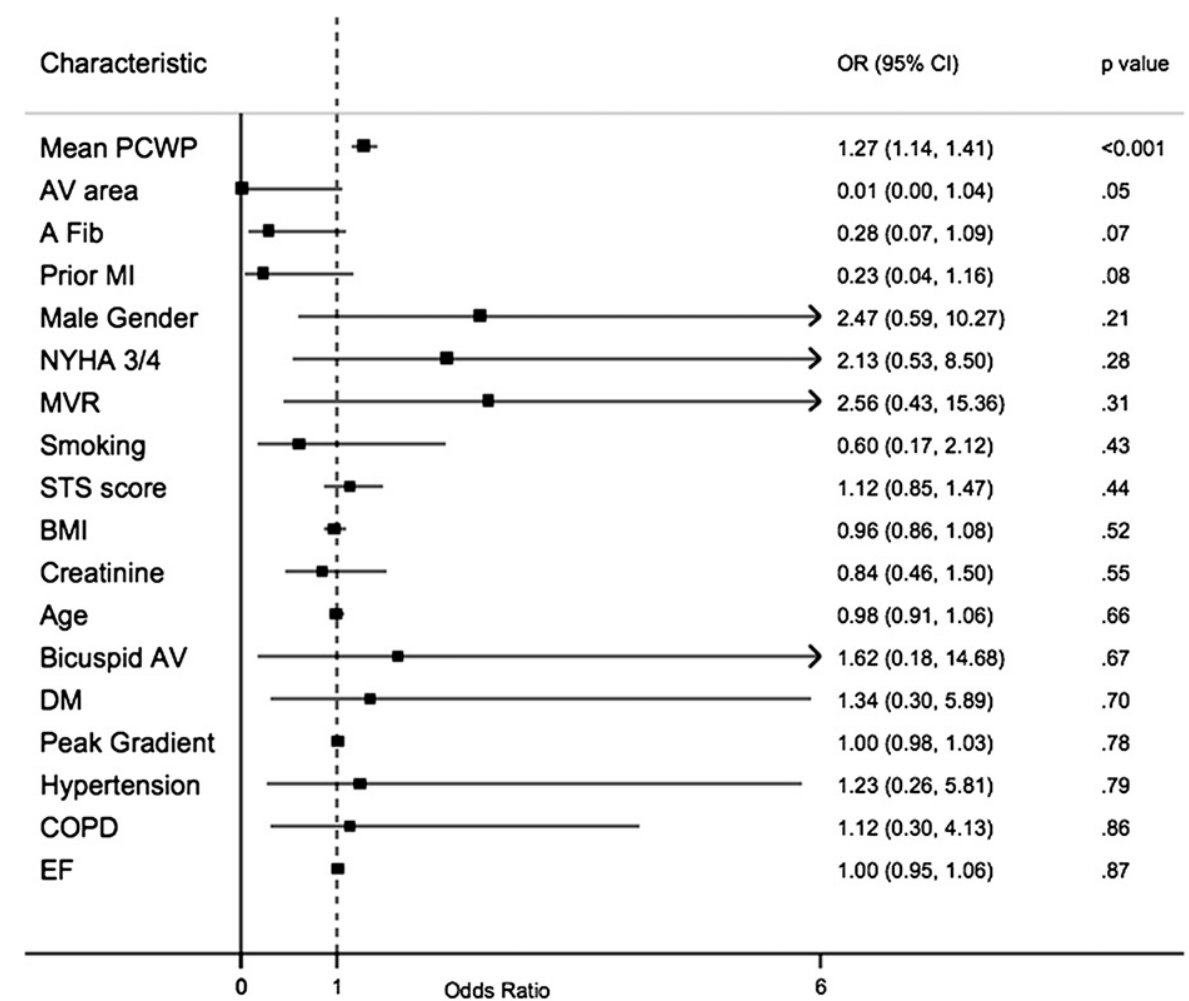

FIGURE 4. Multivariate logistic regression analysis for preoperative predictors of reduction in mean PAP. According to the reduction of mean PAP, the entire study population was divided into 2 groups: responders (patients with $\geq 10 \mathrm{~mm} \mathrm{Hg}$ reduction after AVR) and nonresponders (patients with $<10 \mathrm{~mm}$ $\mathrm{Hg}$ reduction after AVR). 
survival curves of patients with severe AS who underwent AVR were similar, irrespective of their PAP. ${ }^{16}$ These 2 studies compared only medical treatment with surgical AVR in patients with severe AS and severe $\mathrm{PH}$. In addition to this comparison, our study compared the mild-moderate $\mathrm{PH}$ group with the severe $\mathrm{PH}$ group in patients with severe AS who underwent surgical AVR. Le Tourneau and colleagues $^{21}$ assessed the impact of cardiovascular risk factors on early and late outcomes in severe AS after AVR. In their study, systolic PAP was a predictor of mortality in univariate analysis. But, in multivariate analysis, only age, diabetes, male gender, and NHYA class remained as independent predictors of mortality. Two small cardiac catheterization database studies evaluating post-AVR mortality differences in patients with severe AS showed similar mortality in both the mild and severe PH groups. ${ }^{1,4}$ Even the STS risk score included PAP in the calculation to January 2009, but the most recent calculator does not include PAP for risk assessment. ${ }^{11}$

Our study is the first large hemodynamic database study to analyze the impact of $\mathrm{PH}$ in patients with severe AS. Right heart catheterization enabled direct measurement of PAP and PCWP. Unlike previous cardiac catheterizationbased studies that reported only operative mortality, ${ }^{1,4}$ we report long-term mortality results. We showed that patients with AS and severe preoperative $\mathrm{PH}$ had mortality similar to those with mild-to-moderate preoperative PH after AVR. Furthermore, we observed that baseline $\mathrm{PH}$ does not affect survival in these patients after AVR. The current study also reported PAP after surgery from invasive pressure measurements. Multivariable analysis, made possible by the larger sample size, suggested that severe $\mathrm{PH}$ is reactive to increased LVEDP in these patients and rapidly declines after surgery. Reduction in mean PAP was one of the independent predictors of survival after AVR and was seen in patients with severe $\mathrm{PH}$ and patients with mild-to-moderate $\mathrm{PH}$. In the severe PH group, 4 of 5 patients who died after AVR ( 1 died of intestinal ischemia and bleeding, and 3 died of cardiopulmonary failure) still had high postoperative mean PAP. Furthermore, patients with a higher preoperative PCWP had a tendency for greater postoperative reduction in mean PAP. The last reading from the Swan-Ganz catheter was used as the final PAP measurement, which in turn was used to calculate the decrease in mean PAP. Because left ventricle remodeling requires time after the surgery, measuring the change in PAP in the immediate postoperative may underestimate response. Despite this limitation, an early decrease in PAP leads to better long-term outcomes.

Severe PH should not be a contraindication for AVR in patients with severe AS, especially if there is increased filling pressures as measured by higher PCWP. Patients with severe AS who have severe PH can undergo AVR with low mortality and derive substantial benefit from the surgery. Patients who show a higher postoperative reduction in their mean PAP have notably better prognosis. The magnitude of reduction in mean PAP can provide an early indication for success. It seems that AVR provides substantial benefit to these patients.

\section{Limitations}

Our study is a retrospective observational study; thus, the physician bias in patient selection is unavoidable. Similarly, because of the relatively small sample size, we might not have accounted for all confounding variables. We are unable to answer completely the question of how physicians selected these patients to undergo AVR compared with those with PH who did not undergo AVR.

At the Cleveland Clinic, most patients with severe AS undergo only left heart catheterization before surgery. Right heart catheterization is reserved for patients with questions regarding cardiac hemodynamics, including PAP, cardiac output, or AVA. This group of patients is therefore preselected with hemodynamic question. We did review the mortality of all patients undergoing only left heart catheterization in the study period to understand the selection process. Among these patients, postoperative 30-day and 1-year mortality were $1.8 \%$ and $8.5 \%$, respectively. Survival of patients who had only left heart catheterization was significantly better than survival of patients who underwent both left and right heart catheterization $(P=.004)$. $\mathrm{Pa}$ tients undergoing right heart catheterization were high-risk patients for AVR as evidenced by worse survival of the study group compared with all patients undergoing AVR in the same period. The high mortality at 1 year even in patients with mild-to-moderate $\mathrm{PH}$ also signifies that these patients have many comorbidities.

\section{CONCLUSIONS}

The prognosis of patients with severe AS and PH who did not undergo AVR is poor. Potential benefits of AVR may outweigh the risk of surgery, with survival comparable to that of other high-risk patients with nonsevere $\mathrm{PH}$ if other comorbidities do not prohibit operation. Higher preoperative PCWP predicts a more marked reduction in mean PAP, which ultimately predicts improved survival. Therefore, patients with severe $\mathrm{PH}$ should seriously be considered for AVR especially if the PCWP is high. It seems that PH is reactive in a majority of these patients with rapid decline after AVR.

\section{References}

1. Aragam JR, Folland ED, Lapsley D, Sharma S, Khuri SF, Sharma GV. Cause and impact of pulmonary hypertension in isolated aortic stenosis on operative mortality for aortic valve replacement in men. Am J Cardiol. 1992;69:1365-7.

2. Basu B, Cherian G, Krishnaswami S, Sukumar IP, John S. Severe pulmonary hypertension in advanced aortic valve disease. Br Heart J. 1978;40:1310-3.

3. Faggiano P, Antonini-Canterin F, Ribichini F, D'Aloia A, Ferrero V, Cervesato E, et al. Pulmonary artery hypertension in adult patients with symptomatic valvular aortic stenosis. Am J Cardiol. 2000;85:204-8. 
4. Johnson LW, Hapanowicz MB, Buonanno C, Buonanno C, Bowser MA, Marvasti MA, et al. Pulmonary hypertension in isolated aortic stenosis. Hemodynamic correlations and follow-up. J Thorac Cardiovasc Surg. 1988;95:603-7.

5. Silver K, Aurigemma G, Krendel S, Barry N, Ockene I, Alpert J. Pulmonary artery hypertension in severe aortic stenosis: incidence and mechanism. Am Heart J. 1993;125:146-50.

6. McHenry MM, Rice J, Matlof HJ, Flamm MD Jr. Pulmonary hypertension and sudden death in aortic stenosis. Br Heart J. 1979;41:463-7.

7. Svensson LG, Blackstone EH, Cosgrove DM 3rd. Surgical options in young adults with aortic valve disease. Curr Probl Cardiol. 2003;28:417-80.

8. Bouma BJ, van Den Brink RB, van Der Meulen JH, Verheul HA, Cheriex EC, Hamer HP, et al. To operate or not on elderly patients with aortic stenosis: the decision and its consequences. Heart. 1999;82:143-8.

9. Iung B, Cachier A, Baron G, Messika-Zeitoun D, Delahaye F, Tornos P, et al. Decision-making in elderly patients with severe aortic stenosis: why are so many denied surgery? Eur Heart J. 2005;26:2714-20.

10. Kapadia SR, Tuzcu EM. Transcatheter aortic valve implantation. Curr Treat Options Cardiovasc Med. 2009;11:467-75.

11. Svensson LG. Evolution and results of aortic valve surgery, and a 'disruptive' technology. Cleve Clin J Med. 2008;75:802-4.

12. Copeland JG, Griepp RB, Stinson EB, Shumway NE. Long-term follow-up after isolated aortic valve replacement. J Thorac Cardiovasc Surg. 1977;74:875-89.

13. Tracy GP, Proctor MS, Hizny CS. Reversibility of pulmonary artery hypertension in aortic stenosis after aortic valve replacement. Ann Thorac Surg. 1990;50:89-93.
14. Malouf JF, Enriquez-Sarano M, Pellikka PA, Oh JK, Bailey KR, Chandrasekaran $\mathrm{K}$, et al. Severe pulmonary hypertension in patients with severe aortic valve stenosis: clinical profile and prognostic implications. J Am Coll Cardiol. 2002;40:789-95.

15. Snopek G, Pogorzelska H, Zielinski T, Rajecka A, Korewicki J, Biederman A, et al. Valve replacement for aortic stenosis with severe congestive heart failure and pulmonary hypertension. J Heart Valve Dis. 1996;5:268-72.

16. Pai RG, Varadarajan P, Kapoor N, Bansal RC. Aortic valve replacement improves survival in severe aortic stenosis associated with severe pulmonary hypertension. Ann Thorac Surg. 2007;84:80-5.

17. Celermajer DS, Marwick T. Echocardiographic and right heart catheterization techniques in patients with pulmonary arterial hypertension. Int $J$ Cardiol. 2008;125:294-303.

18. Budev MM, Arroliga AC, Jennings CA. Diagnosis and evaluation of pulmonary hypertension. Cleve Clin J Med. 2003;70:S9-17.

19. Schannwell CM, Steiner S, Strauer BE. Diagnostics in pulmonary hypertension. J Physiol Pharmacol. 2007;58:591-602.

20. Barst RJ, McGoon M, Torbicki A, Sitbon O, Krowka MJ, Olschewski H, et al. Diagnosis and differential assessment of pulmonary arterial hypertension. J Am Coll Cardiol. 2004;43:40S-7.

21. Le Tourneau T, Marechaux S, Vincentelli A, Ennezat PV, Modine T, Polge AS, et al. Cardiovascular risk factors as predictors of early and late survival after bioprosthetic valve replacement for aortic stenosis. J Heart Valve Dis. 2007;16: 483-8. 